\title{
Effects of experiential food education on local food purchasing and eating behavior
}

\author{
Amy Joy Lanou a \\ University of North Carolina Asheville and North Carolina Center for Health and Wellness
}

Leah Greden Mathews b*

University of North Carolina Asheville

Jessica Speer ${ }^{\mathrm{c}}$

Research Triangle Institute

Lance Mills ${ }^{\mathrm{d}}$ and Nicholas Gold-Leighton ${ }^{\mathrm{e}}$

University of North Carolina Asheville

Submitted July 29, 2019 / Revised February 10, 2020, and March 17 and May 10, 2021 /

Accepted May 12, 2021 / Published online September 9, 2021

Citation: Lanou, A. J., Mathews, L. G., Speer, J., Mills, L, \& Gold-Leighton, N. (2021).

Effects of experiential food education on local food purchasing and eating behavior.

Journal of Agriculture, Food Systems, and Community Development, 10(4), 211-224.

https://doi.org/10.5304/jafscd.2021.104.006

Copyright (C) 2021 by the Authors. Published by the Lyson Center for Civic Agriculture and Food Systems. Open access under CC-BY license.

\author{
Abstract \\ Using self-reported health and economic behav- \\ iors, this study explores the extent to which experi- \\ ential food activities such as cooking new foods \\ and attending farmers markets impact local food \\ consumption, purchasing, and eating behaviors. \\ a Amy Joy Lanou, Professor, Department of Health and \\ Wellness Promotion, University of North Carolina Asheville, \\ and Executive Director, North Carolina Center for Health and \\ Wellness; CPO \#4030; Asheville, NC 28804 USA; +1-828- \\ 250-2317; alanou@unca.edu \\ $\mathrm{b} *$ Corresponding author: Leah Greden Mathews, Professor and \\ Chair, Department of Economics; 147 Karpen Hall, \\ University of North Carolina at Asheville; Asheville, NC \\ 28804 USA; +1-828-251-6551; 1 mathews@unca.edu \\ c Jessica Speer, Economist, Research Triangle Institute; 5 East \\ Monroe Ave. \#208; Alexandria, VA 22301 USA; \\ jlspeer@rti.org
}

This longitudinal survey includes pre/post intervention surveys administered to a convenience sample of 55 community members, categorized as "young adults," "adults," and "older adults." The 41-item baseline survey includes closed-ended questions regarding food preference, purchasing

\footnotetext{
d Lance Mills, Grounds Crew Worker, University of North Carolina Asheville; One University Heights; Asheville, NC 28803 USA; $\underline{\text { lmills1@unca.edu }}$

e Nicholas Gold-Leighton, Student Health Ambassador Project Manager; University of North Carolina Asheville; 121 Hendersonville Road; Asheville, NC 28803 USA; kol.gold@mahec.net

\section{Funding Disclosure}

Research funding was provided by a 2014-2015 North Carolina Center for Health and Wellness Focus Area Grant and the Interdisciplinary Distinguished Professorship of the Mountain South at the University of North Carolina Asheville.
} 
habits, and general awareness. The 54-item post survey, administered after participating in the study, includes the same closed-ended questions as the pre-survey, as well as open-ended questions regarding participants' perceived impact of the intervention on their behaviors. Data was analyzed with paired t tests, one-way ANOVA, paired proportional analysis using McNemar's Test, Bonferroni correction tests, and normality tests. Survey results show significant positive change $(\mathrm{p}<0.001)$ in overall eating, preparation, and purchasing behaviors from baseline to post-study. These findings appear to demonstrate that simple, low-cost interventions to engage adults in learning about and experiencing local food can lead to a change in shopping and pro-local eating behaviors.

\section{Keywords}

Behavior Change, Consumer Behavior, Experiential Learning, Local Food

\section{Introduction and Literature Review}

The number of U.S. farmers markets has increased 395\% from 1994 to 2017 (U.S. Department of Agriculture Economic Research Service [USDA ERS], 2017), providing considerable additional access to fresh, healthy, whole foods. Consumers attend farmers markets for a variety of reasons: to buy fresh local food, support the local economy, satisfy concerns about the food supply through direct interaction with vendors, and enjoy the social atmosphere of the markets (Kirby et al., 2007). However, consumers cite concerns about price, location, market days and hours, and demographic homogeneity (Wetherill \& Gray, 2015), as reasons for not using farmers markets or seeking out local foods (Jilcott Pitts et al., 2014; McGuirt et al., 2014). Mobile markets have been successfully utilized to overcome the location barrier and increase fruit and vegetable consumption among individuals living in rural communities (Leone et al., 2018).

There are a variety of motivations to engage in local food and farmers markets. Local foods have been promoted effectively through socially based motivations such as price, freshness, market friendliness, and taste (D. Adams \& A. Adams, 2011; Wolf et al., 2005). Previous studies show that accessibility and consumer attitudes towards certain foods are the main determinants of whether target audiences purchase local foods (D. Adams \& A. Adams, 2010). The social interactions and personal connections that consumers establish with food producers promote consumer willingness to purchase local foods (Carson et al., 2016). Despite increased accessibility to local foods, consumers will choose pre-prepared meals if they are incapable of preparing meals or using food in new ways (Rainbolt et al., 2012).

In previous reports, non-student female farmers market shoppers in a university town (Jilcott Pitts et al., 2013) and adult farmers market shoppers from racially and socioeconomically diverse rural communities (Cromp et al., 2016; Jilcott Pitts et al., 2017; McCormack et al., 2010; McGuirt et al., 2014), reported higher fruit and vegetable intake than non-farmers market shoppers. The magnitude of the difference is appreciable. In a 2017 study, average fruit and vegetable intake was $5.5 \pm 2.2$ servings/day among market-goers who reported shopping at farmers markets two or more times per week, compared to $4.4 \pm 1.7$ servings/day for those who reported shopping a few times a year or less (Jilcott Pitts et al., 2017). In some regions, local food consumption has increased per capita through the availability of these food ingredients in restaurants, grocery stores, and school food services with direct sale operations (Kirby et al., 2007). While the use of farmers markets and the purchase of local food in other settings has increased, many people still do not make the choice to eat healthfully. Nutritionists and health promoters have attempted to eliminate gaps between access and choice through education efforts; food producers and economists are advocating for reducing transaction costs, the time and effort needed to make choices or purchases; and for increasing the accessibility of healthier food options. Some of these efforts are focused on teaching individuals how to use daily behaviors to "nudge" themselves into a new routine or experience that provides lasting healthful personal change.

Behavioral economic studies have identified three behavioral biases relevant to food behaviors: present-biased preferences (Engell et al., 1996; Levitz, 1976; Meiselman et al., 1994), visceral fac- 
tors such as emotions and drives (Lambert et al., 1991; Shiv \& Fedorikhin, 2002), and-most relevant to the present study-status quo bias and default options (Raynor \& Wing, 2007; Schachter $\&$ Gross, 1968). Status quo bias is a powerful force on individual preferences, leading one to stick with current or default options (Kahneman, 2003) even when transition costs are low or the importance of the decision is great. Samuelson and Zeckhauser (1988) note that status quo bias is consistent with loss aversion, and that it could be psychologically explained by previously made commitments, sunkcost thinking, cognitive dissonance, a need to feel in control, and regret avoidance. The latter is based on Kahneman and Tversky's (1982) observation that people feel greater regret for bad outcomes that result from new actions taken than for bad consequences that are the consequence of inaction. One vehicle for changing food behavior is "nudging" oneself into a new behavior pattern by changing the environment in which a food choice occurs (Thaler \& Sunstein, 2009). For example, the effectiveness of using a change in default options to modify the amount of food consumed has been demonstrated. Rolls (2003) and Rolls et al. (2006) found that decreasing meal portion size led to a reduction in the total amount of food consumed; similar results can be found when reducing sandwich size (Rolls, Roe, \& Meengs et al., 2004) and snacks (Rolls, Roe, \& Kral et al., 2004). Serving containers also seem to matter: individuals eating M\&Ms out of larger containers ate $129 \%$ more than those with smaller containers (Marchiori et al., 2012).

In order to change more complex eating behaviors, such as purchasing, preparing, and eating healthier meals from local foods, the individual must relinquish old patterns and adopt new ones (Thaler \& Sunstein, 2009). These behavior changes will take more than just written nutrition information or classroom nutrition education to take hold. For example, efforts to improve front-ofpackage information or add nutrition labeling to restaurant menus have had inconsistent impact on energy intake. Liu et al. (2014) noted that "at best, existing information-provision policies have the potential to modestly influence individuals' food choices" (p. 2).
Experiential learning has shown promise for providing the necessary nudge to change status quo or default options, both for understanding the food system (Maher \& Burkhart, 2017) and changing eating behaviors (Reicks et al., 2014). The theory of experiential education posits that acting, experiencing (or feeling), thinking and reflecting act in tandem to create learning (A. Kolb \& D. Kolb, 2005). Experiences with food such as tastings, cooking classes, attending farmers markets and talking with farmers, growing and harvesting food, and other food experiences are likely effective at inducing healthy food behavior change because they allow individuals to "reset" their food behaviors. Our hypothesis is that once food experiences have been incorporated into one's life, there is a new status quo.

If one is able to reset food experiences, research suggests that a change in behavior is likely to follow. Based on an association between higher cooking skills and higher vegetable and lower convenience food consumption, Hartmann and her colleagues (2013) suggest that cooking skills may help individuals to meet nutrition guidelines. In other studies, experiential cooking and nutrition education has been shown to increase cooking selfefficacy and vegetable consumption for children in grades 3-8 (Jarpe-Ratner et al., 2016), increase cooking skills and confidence among cooks in African American churches (Condrasky et al., 2013), and has shown promise for improving one or more nutrition-related health behaviors in a review of 28 studies of cooking interventions (Reicks, 2014). Similarly, confidence in cooking vegetables is associated with higher vegetable purchasing for households; teaching these cooking skills may be a useful strategy for increasing fruit and vegetable consumption (Winkler \& Turrell, 2009). A study found that young adults who purchased their own food and prepared food at home more often had better diet quality than those who did not (Larson et al., 2006).

Economists and health promoters can learn from each other how to merge efforts to encourage behavior change to support health. Thomson and Ravia (2011) found that behavioral interventions to increase fruit and vegetable intake led to slightly higher mean increase for adult participants (1.13 
servings fruit and vegetable intake/day), and concluded that behavior-based interventions alone are not likely to result in the long-term sustained changes in fruit and vegetable intake needed to meet dietary guidelines. They further concluded that nutrition education efforts appear to be more effective at changing eating patterns when they are paired with behavioral economic approaches. In a report addressing the challenges and benefits to participants of following a 100-mile diet for four weeks, Byker et al. (2010) note that a diverse array of both capacity-building and education strategies are needed to bring local food consumption into mainstream behaviors.

Recognizing practical knowledge gained from healthy local food experiences as a potential mechanism for change, we consider the pathway to dietary behavior change through encouraging food experiences with a local food system. The study location supports a thriving local food system with many opportunities to purchase local food at farmers markets and in restaurants and grocery stores. We leveraged this location to ask: Can a simple low-cost intervention to engage adults in learning about, and having direct experiences with healthy local food, lead to changes in thinking about shopping and eating, and perhaps also to more healthful eating practices?

\section{Research Methods}

\section{Study Design}

In the Asheville, North Carolina, area in the Southeastern United States, where this study was done, there are 10 markets each week in season (April through December), three weekly winter markets, and two holiday markets from November through December. Direct-to-consumer sales of local food in the region grew an astonishing 69\% from $2007-$ 2012 (Jackson, 2015) and the number of farms listed in a local food guide for the Western North Carolina and Southern Appalachian regions rose from 211 in 2008 to 603 in 2016 (Perrett et al., 2018).

We utilized a pre-/post-survey design to assess the impact of a local food promotion intervention at the University of North Carolina Asheville (UNCA), a public liberal arts university. The program was designed to engage participants in local food, food system, and healthy food choice-related activities over a 5-month period. The activities involved in the study were open to the entire community; therefore, to conduct the study with a control group would have required recruitment of a comparison community, which was outside the budget for this project. Thus the study relied on a convenience sample in which we assumed that some participants would be unable to attend events, effectively providing a natural experiment or within-population "natural" control group. Once enrolled, participants were asked to complete an online survey via SurveyMonkey and were emailed a newsletter at approximately 2 -week intervals announcing upcoming food-related events. ${ }^{1} \mathrm{~A}$ menu of opportunities was provided to participants to allow for the type of libertarian paternalism or freedom of choice described by Thaler and Sunstein (2009). Some of the 31 events were hosted by the researchers and others were scheduled by campus and community groups; events included eight on-campus lectures, eight cooking or gardening classes, five community events related to local food and agriculture, eight food tastings on campus or at local stores, and two food-related film screenings. The newsletters also offered information about both winter and spring tailgate markets in order to promote participant familiarity with the location and hours of area tailgate markets, especially the winter markets. The common element across the experiential learning events was a focus on learning about healthful eating and/or local food availability through cooking, tasting, growing, and discussing food and health. Participants were asked to attend at least one food event during the five-month period and were provided an incentive (a chance to win a gift card to a local market) for completing the post-test survey. Because of a relatively short study period, which facilitated participant recall, we relied on participants to self-report event attendance data for data analysis.

${ }^{1}$ Recruitment material, newsletters, and other materials are available by request from the corresponding author. 


\section{Participants and Recruitment Methods}

Using a convenience sampling strategy, participants were recruited using posters and through emails sent to faculty, staff, and students of UNCA and its Osher Lifelong Learning Institute (OLLI), a continuing education program for older adults located on campus. Participants were also recruited at seasonal food tastings on campus and at a kick-off event at OLLI. The study was approved with an expedited review by the Institutional Review Board at UNCA. Written consent was obtained from participants.

Overall, 244 individuals expressed interest in the study, of whom 151 enrolled and completed the baseline survey and 79 completed the post survey. While 71 participants filled out both the baseline and post survey, only 55 paired responses were usable for the composite statistical analysis. ${ }^{2}$ These responses were grouped into three age categories: college-age and young adults ( $<25$ years), adults (25-59 years), and older adults ( $>59$ years). Table 1 presents demographic data about the 55 participants.

\section{Survey Instruments}

A 41-item baseline survey was used to gather information about food preferences, awareness, and purchasing habits. Participants were asked to rate

Table 1. Participant Demographics $(n=55)$

\begin{tabular}{lc}
\hline Age Group & Number of Participants \\
\hline College-aged and young adults (<25 years) & 13 \\
\hline Adults (25-59 years) & 25 \\
\hline Older adults (>59 years) & 17 \\
\hline Gender of Participants & 47 \\
\hline Female & 8 \\
\hline Male & \\
\hline Participants' University Affiliation & 21 \\
\hline Student & 18 \\
\hline Employee & 15 \\
\hline Attend OLLI & 1 \\
\hline No Affiliation & \\
\hline
\end{tabular}

their knowledge about local food procurement, their food shopping, consumption and preparation habits, preferences for local or organically produced food, and dietary restrictions and preferences. The 54-item post-survey included the baseline survey questions plus open-ended questions regarding participant attendance at events and the impacts of attendance on eating and purchasing food. In these questions, participants were asked if they perceived a change in their behavior, and what kinds of changes they perceived.

\section{Data Analysis}

In order to test for changes in behaviors, select responses to survey questions were coded using either an ordinal or dichotomous scale as outlined in Table 2. For each participant, composite scores using 12 variables were compiled by calculating the sum of the numeric values associated with each response of the variables chosen for analysis (Table 2). A paired t test was utilized to determine if a change in mean composite scores occurred during the study period. When the data was not normally distributed, a signed rank test was used as the nonparametric equivalent of the paired $t$ test, as the signed rank test does not require normal distribution to determine if the mean change in scores is significant.

Two variable groups were formed representing two distinct types of behavior change: changes in local food purchasing/preparation and health/ food choices. The five variables related to local food purchasing/preparation and the five variables related to health/food choices were analyzed separately (Table 2). The internal consistency of these subgroups-in addition to the overall variable grouping-was tested utilizing McDonald's omega, a test that estimates scale reliability (Dunn et al., 2014). The McDonald's omega result for all variables ranged between .7 and .8 for baseline and post-tests, which is

\footnotetext{
${ }^{2}$ A demographic comparison of enrolled participants who completed baseline, post, and paired surveys is in Appendix Table A1.
} 
Table 2. Survey Variable and Coding

\begin{tabular}{|c|c|c|c|}
\hline Variable & Description & Coding/Assignment & Composite Variable \\
\hline \multicolumn{4}{|c|}{$\begin{array}{l}\text { Overall Composite Group (12 Variables) } n=55 \\
\text { Mean change }=2.36 \pm 0.49 ; p<.001\end{array}$} \\
\hline \multicolumn{4}{|c|}{$\begin{array}{l}\text { Health/Food Choice Subgroup }(n=55) \\
\text { Mean change }=0.50 \pm 0.31 ; p=.11\end{array}$} \\
\hline FRUIT & How often the participant eats fruits & $\begin{array}{l}0=\text { Rarely } \\
1=<3 \text { times/week }\end{array}$ & Overall score \\
\hline VEG & How often the participant eats vegetables & $\begin{array}{l}2=3-5 \text { times } / \text { week } \\
3=\text { About once/day } \\
4=2 \text { or } 3 \text { times } / \text { day } \\
5=3-5 \text { times } / \text { day } \\
6=5+\text { times } / \text { day }\end{array}$ & $\begin{array}{l}\text { Health/ Food Choice } \\
\text { subgroup }\end{array}$ \\
\hline CONFID & $\begin{array}{l}\text { Self-reported confidence level in ability to make healthy } \\
\text { food choices }\end{array}$ & $\begin{array}{l}1 \text { (Not confident)-10 } \\
\text { (Very confident) }\end{array}$ & Overall score \\
\hline CHOICE & $\begin{array}{l}\text { Self-reported likelihood of the participant regularly } \\
\text { making healthy food choices }\end{array}$ & & $\begin{array}{l}\text { Health/ Food Choice } \\
\text { subgroup }\end{array}$ \\
\hline PREP & $\begin{array}{l}\text { Percentage of meals the participant cooked or otherwise } \\
\text { prepared for themselves }\end{array}$ & $\begin{array}{l}0=0 \%-5 \% \\
1=5 \%-20 \% \\
2=20 \%-35 \% \\
3=35 \%-50 \% \\
4=50 \%-75 \% \\
5=75 \%-100 \%\end{array}$ & $\begin{array}{l}\text { Overall score } \\
\text { Health/ Food Choice } \\
\text { subgroup }\end{array}$ \\
\hline
\end{tabular}

\section{Purchasing Subgroup $(n=55)$}

Mean post-intervention change $=0.75 \pm 0.24 ; p<.001$

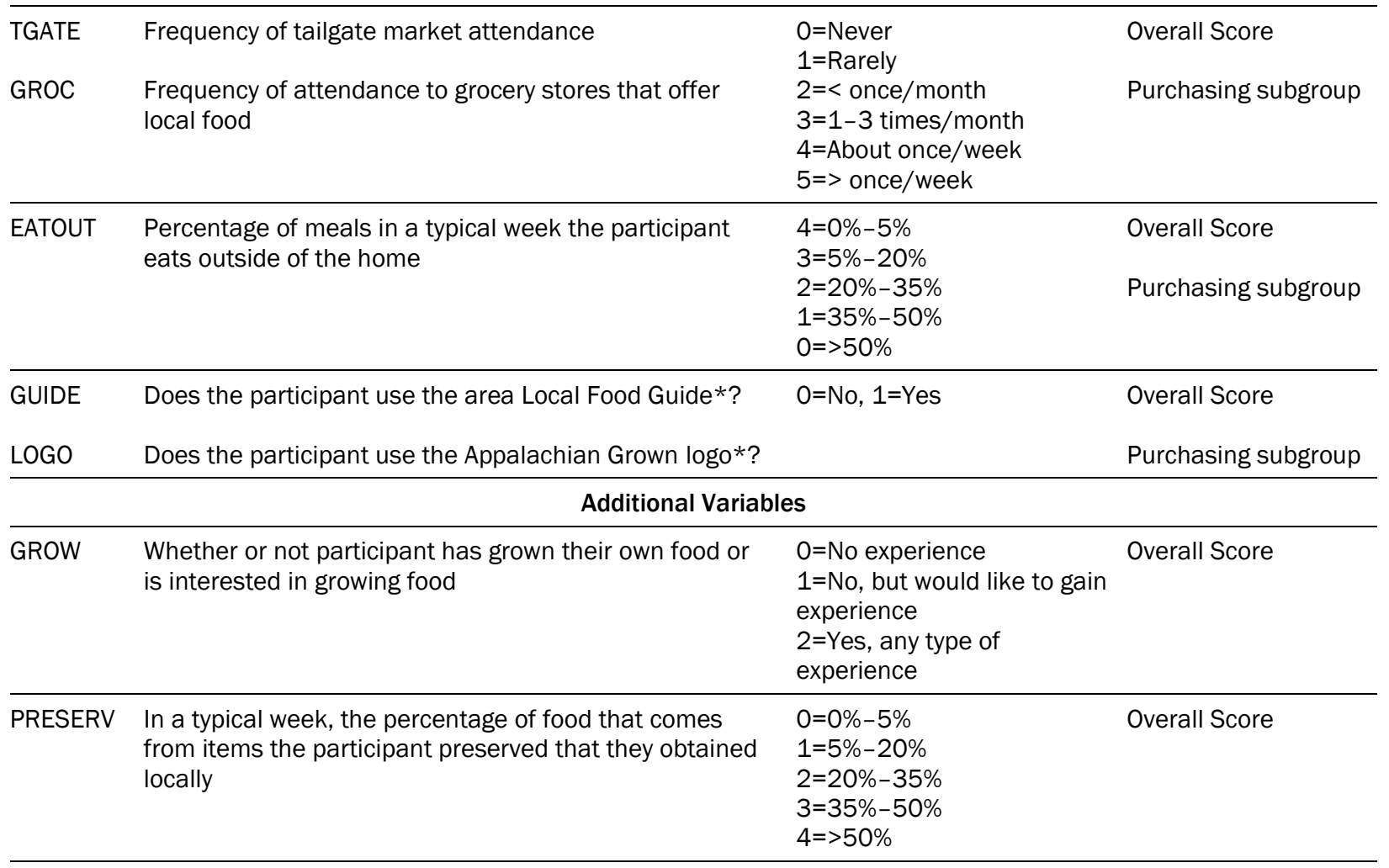

\footnotetext{
* Appalachian Grown Logo and Local Food Guide are projects of the Appalachian Sustainable Agriculture Project, an area nonprofit.
} 
considered acceptable to good (Gadermann et al., 2012; Padilla \& Divers, 2013). This confirmed the usefulness of these variable groupings for our analysis.

Because time is often a limiting factor for individuals, and time constraints can vary by age due to work, parenting, and other commitments, we suspected there may be differences in the way participants responded to the study based on their age. We thus used a one-way analysis of variance (ANOVA) procedure to test for differences among age groups. Those under 25 years were placed in the "young adult" cohort, ages 25 to 59 in the "adult" cohort, and those 60 and above in the "older adult" cohort. In addition, a two-factor ANOVA, also known as factorial analysis, was conducted to assess whether a change in scores was attributable to the study intervention after taking into account various factors. The first factor accounted for the number of events that a participant attended with two levels: above average attendance (the participant attended three or more events) or below average attendance (attending two events or less). The second factor accounted for participant purchasing habits as represented by their self-reported scores upon entering the study with two levels: participants entering with scores above the study group average or below the

\section{Table 3. Frequency of Event Attendance and Event Type $(n=55)$}

\begin{tabular}{lc}
\hline Event Attended & Number of Participants \\
\hline 1 event & 14 \\
\hline 2 events & 9 \\
\hline 3 events or more & 23 \\
\hline Type of Events Attended & $\begin{array}{c}\text { Number of Participants Reporting } \\
\text { Attendance }\end{array}$ \\
\hline Food Tastings & 33 \\
\hline Cooking Classes & 22 \\
\hline Talks or Speaker Events & 49 \\
\hline Other Event & 13 \\
\hline More than one event type & 24 \\
\hline
\end{tabular}

average purchasing score. A paired proportional analysis was conducted using McNemar's test to compare for "before and after" effects on individual fruit consumption, vegetable intake and meal preparation variables. Finally, normality tests were conducted on all variable groups. ${ }^{3}$

Descriptive data was obtained from SurveyMonkey. If participants reported a change in their eating or shopping behavior in the post survey, the types of changes were coded thematically and the number of occurrences of relevant themes such as fresh/local, seasonal, organic, and whole/ healthier choices was determined.

\section{Results}

Over two-thirds (46/55 or $84 \%$ ) of the participants attended at least one food related event (Table 3). Participants attended "other events," such as gardening, homesteading, mushrooming class, local farm or garden tours, visiting tailgate markets, and viewing a documentary film about food 13 times. Baseline and post-study responses to questions about specific eating, cooking, and shopping habits are reported in Table 4.

The result of the paired t-test on the overall composite group (12 variables; coding in Table 1) was highly significant $(n=55$; mea $n=2.36 \pm 0.49$; $p<.001$ ), indicating that a positive change in composite scores occurred during the study period. For the purchasing subgroup, the non-parametric signed rank test indicated a significant positive change in scores $(n=55$; mean $=0.75 \pm 0.24$; $p<.001)$. The health/food choice variable group did not indicate a statistically significant change $(n=55 ;$ mean $=0.50 \pm$ $0.31 ; p=.11$ ). However, a difference was observed between participant baseline and post scores for the FRUIT, VEG, and PREP variables (Table 2). To assess whether this difference was statistically significant, a two-proportion test for paired samples was conducted on each variable. The results of the McNemar's

\footnotetext{
${ }^{3}$ A Bonferroni correction was performed on procedures utilized more than two times within the analysis to reduce the chance of committing a Type I ("false positive") error. The cutoff for significance for the paired t tests and McNemar's Tests were 0.0167 after the Bonferroni correction, as they were utilized three times.
} 
Table 4. Baseline and Post Study Healthy Eating, Local Purchasing and Other Characteristics (\% participants; $n=55$ )

\begin{tabular}{|c|c|c|c|}
\hline Health/Food Choice Subgroup of Healthy Eating Characteristics & Baseline & Post & $\begin{array}{l}\text { Percentage } \\
\text { Point Change }\end{array}$ \\
\hline Eating fresh fruit 2 or more times/day (FRUIT) & $42 \%$ & $47 \%$ & +5 \\
\hline Eating fresh vegetables 2 or more times/day (VEG) & $58 \%$ & $64 \%$ & +6 \\
\hline Preparing $50 \%$ or more of meals themselves (PREP) & $81 \%$ & $85 \%$ & +4 \\
\hline Mean confidence in ability to make healthy choices (CONFID) & 8.64 & 8.75 & - \\
\hline Mean likeliness to regularly make healthy choices (CHOICE) & 7.44 & 7.69 & - \\
\hline Purchasing Subgroup of Local Purchasing Characteristics & Baseline & Post & \\
\hline Shopping at local tailgates at least once/week (TGATE) & $13 \%$ & $18 \%$ & +5 \\
\hline Shopping at groceries with local food at least once/week (GROC) & $62 \%$ & $73 \%$ & +11 \\
\hline Eating $>20 \%$ of meals outside of the home each week (EATOUT) & $25 \%$ & $15 \%$ & -10 \\
\hline Using local food guide to shop (GUIDE) & $38 \%$ & $51 \%$ & +13 \\
\hline Using the Appalachian Grown logo to find local products (LOGO) & $45 \%$ & $67 \%$ & +22 \\
\hline Gardening and Food Preservation Characteristics & Baseline & Post & Change \\
\hline Currently growing or planning to grow food (GROW) & $85 \%$ & $85 \%$ & - \\
\hline $\begin{array}{l}\text { Twenty percent or more of food eaten comes from items canned, dried, frozen, or } \\
\text { otherwise preserved obtained locally (PRESERV) }\end{array}$ & $10 \%$ & $20 \%$ & +10 \\
\hline
\end{tabular}

Test indicate that while there was no statistically significant difference in FRUIT or VEG, a significant increase did occur within the PREP variable $(\mathrm{p}<.001)$, indicating that participants were preparing more meals for themselves. The one-way ANOVA procedure did not show significant differences among age groups, suggesting all age groups had similar increases in scores.

A two-factor ANOVA was conducted on the purchasing subgroup, as the signed rank test showed a significant increase in scores among this subgroup. Significant main effects were observed for both event attendance $(p=.022)$ and the participant's score upon entering the study ( $p=.004)$, signifying that the observed increase in scores can be attributed to the intervention and that a participant's entry score had an effect on the observed increase in scores. The results indicate that those with below average purchasing entry scores and above average event attendance had significantly higher increases in scores compared with the two cohorts who entered with above average scores (Mean Difference: 2.45; 95\% Confidence Interval: $0.64,4.26 ; p=.004)$, especially when compared to the cohort with above average entry scores and below average attendance (Mean Difference: 2.02, 95\% Confidence Interval: 0.07, 3.97, $p=.040$ ).

When asked about perceived changes in the post-survey, $34 \%$ of participants indicated they had made a change in their eating habits $(16 \%$ were unsure), and $45 \%$ of participants indicated they had made a change in shopping habits $(12 \%$ were unsure). Reported changes in eating habits varied across individuals, with participants reporting changes such as eating more fresh and local food, greater consciousness of what was being eaten, choosing more organic food, cooking at home more frequently, becoming more adventurous with eating choices, and eating more seasonally.

\section{Discussion}

This study focused on the impact of education, in terms of where to purchase local food and how to prepare it; this education effectively reduces some of the upfront time and effort, or transaction costs, which people face when attempting to make a behavior change toward eating more healthy and local food. Our results indicate that in an area with 
good access to local food, engaging people in educational food experiences leads to positive behavior changes in food-related behaviors. Clear evidence of this result is seen in the overall composite score of 12 health and food behaviors, which exhibited significant improvement from baseline during the course of the study. Because composite score increases were the same for participants in each age cohort, the study did not yield differential impacts on participants belonging to different age groups. We interpret these results to mean that a simple, low-cost intervention to engage adults in food experiences can assist individuals with adopting new food behaviors. The newsletter provided a streamlined communication mechanism that helped to reduce the transaction-i.e., search and identify_costs of participating in a food event or attending a farmers market.

Participants demonstrated a significant change in the composite subgroup score that measured food purchasing behaviors. Post-study gains reported by participants include more frequent tailgate market attendance ( $6 \%$ of respondents), increased visits to grocers that offer local food products ( $11 \%$ of respondents), and more frequent dining at restaurants that offer local food at least once/week (4\%), which suggest greater intention around local food selection. In addition, more participants reported increased familiarity with the local food guide and Appalachian Grown logo, both of which can facilitate the purchase of local food products, and thus an indicator of a more purposeful engagement with the local food system. In fact, at the conclusion of the study more participants were using the local food guide $(13 \%)$ and the Appalachian Grown logo (22\%) to shop and find local products This result is likely due to the successful programming of our community partner, the Appalachian Sustainable Agriculture Project (ASAP), and the fact that the study took place in an area with abundant opportunities to engage with the local food system and purchase local food.

Improvements in purchase behavior were impacted by both the baseline behaviors reported by participants and the number of events they attended during the study period. Participants with below-average purchasing entry scores who attended an above-average number of events reported the most significant gains in food-related purchasing behaviors and preferences. This result is intuitive, as those who have more to learn have more to gain from participation in a study that is designed to encourage more healthful choices and local food behaviors.

The lack of statistically significant change in the Health/Food Choice subgroup may have been due to a "ceiling effect" (Schweizer et al., 2019; Wang et al., 2008). Participants who entered the study reporting high frequency for the health/food choice behaviors (e.g., scores on the higher end of the reporting range in this variable group) indicated less opportunity for improvement in these measures. This result is consistent with transaction cost theory, which suggests that reducing costs of acquiring information (in this case, about cooking) will lead to more activity. The result is also consistent with the work of Winkler and Turrell (2009) demonstrating a link between confidence in cooking vegetables and greater vegetable purchasing.

Study participants did not report statistically significant changes in their average fruit and vegetable consumption, which at first glance may seem discouraging. However, $11 \%$ of individuals increased their fruit intake and $24 \%$ increased their vegetable intake by at least one category (data not shown) where a category change is roughly one half to a whole serving per day. This appears to have practical significance when compared with other studies; for example, a meta-analysis conducted by Ammerman et al. (2002) examining the effectiveness of behavioral dietary interventions reported an average increase of 0.6 servings of fruits and vegetables per day. Another reported change that was not statistically significant is that $10 \%$ more participants reported preparing more meals at home post-intervention than at baseline. This may have practical significance because home meal preparation is a marker of more healthful eating habits (Larson et al., 2006) and because engagement with local food supply and food preparation has been shown to offer significant personal enjoyment and pleasure (Byker et al., 2010), which can reinforce these eating behaviors.

The relatively small sample size in this study, due in part to weak participant retention, as well as 
the lack of a control group, limits the generalizability of the results. Participants self-selected into the study, perhaps due to an enthusiasm for learning about healthy food behaviors and local food systems, which means they may have been wellprimed for the intervention or were already contemplating a change in their food behaviors. In addition, because the study recruitment occurred in January, participants may have self-selected into the study as part of a desire to support a health- or local food-focused intention which may come with the new year. A community "vibe" that is pro-local food may have also served to prime study participants to be more open to a change in food behaviors than would occur in other locations. If any of these factors were prevalent, our results may overstate the impact of the intervention. Replications of this type of study in areas with less vibrant local food systems and/or at other times during the calendar year will help disentangle these potential effects.

Our participants were offered a large number of food activities at very low cost to the researchers because many local food-related activities already occur in our food-conscious community. As a result, replicating this study will be costlier in most other locations.

Participant reporting of significant behavior change despite the short duration of the study (five months) may seem an encouraging endorsement for this intervention because one can see positive impacts in a short period of time. However, the short study duration may also mean that participants were "trying on" new behaviors that may not stick in the long run. If participants are not committed to following through with the reported changes, then they have not fully adjusted their default food behaviors, which means that the impact of the intervention will be overstated. Additionally, participants' high levels of engagement may be attributable to the consistent reminders of oppor- tunities to engage in local food-related events provided by the research team. Without these reminders, favorable behavior gains may decrease or diminish altogether.

\section{Conclusions}

This research suggests that interactions with food systems and food education experiences can change household-level consumption decisions. These apparently small changes lead to noticeable preferences toward healthful lifestyles; in fact, our study results indicate more powerful individual changes than are often seen in studies of nutrition education.

This study's intervention was simple, cheap, and intuitive. Future studies wishing to replicate or extend these results should consider also providing participants with a range of opportunities to engage with food in order to allow for the freedom of choice that appears to be a successful element for public and private institutions to affect behavior change (Thaler \& Sunstein, 2009). Meeting people where they are-whether they are gaining completely new perspectives and information, contemplating a change in behavior, or have already been starting to change behaviors with the aim of improving their health-will provide opportunities for a broader response to health-promoting interventions in local food systems.

\section{Acknowledgments}

Grateful appreciation to our community partners Appalachian Sustainable Agriculture Project, Osher Lifelong Learning Institute at UNC Asheville, and other campus and community organizations who provided educational programming. Thanks also to Laura Sexton and Katie Cox for study support, as well as to the participants. We acknowledge the efforts of the manuscript's anonymous reviewers whose insights improved the paper.

\section{References}

Adams, D. C., \& Adams, A. E. (2011). De-placing local at the farmers' market: Consumer conceptions of local foods. Journal of Rural Social Sciences, 26(2), 74-100. http://journalofruralsocialsciences.org/pages/Articles/JRSS $\% 202011 \% 2026 / 2 / J R S S \% 202011 \% 2026 \% 202 \% 2074$ 100.pdf 
Ammerman, A. S., Lindquist, C. H., Lohr, K. N., \& Hersey, J. (2002). The efficacy of behavioral interventions to modify dietary fat and fruit and vegetable intake: A review of the evidence. Preventive Medicine, 35(1), 25-41. https://doi.org/10.1006/pmed.2002.1028

Byker, C., Rose, N., \& Serrano, E. (2016). The benefits, challenges, and strategies of adults following a local food diet. Journal of Agriculture, Food Systems, and Community Development, 1(1), 125-137. https://doi.org/10.5304/jafscd.2010.011.013

Carson, R. A., Hamel, Z., Giarrocco, K., Baylor, R., \& Mathews, L. G. (2016). Buying in: The influence of interactions at farmers' markets. Agriculture and Human Values, 33(4), 861-875. https://doi.org/10.1007/s10460-015-9675-y

Condrasky, M. D., Baruth, M., Wilcox, S., Carter, C., \& Jordan, J. F. (2013). Cooks training for Faith, Activity, and Nutrition project with AME churches in SC. Evaluation and Program Planning, 37, 43-49. https://doi.org/10.1016/j.evalprogplan.2012.11.002

Cromp, D., Cheadle, A., Solomon, L., Maring, P., Wong, E., \& Reed, K. M. (2016). Kaiser Permanente’s farmers' market program: Description, impact, and lessons learned. Journal of Agriculture, Food Systems, and Community Development, 2(2), 29-36. https://doi.org/10.5304/jafscd.2012.022.010

Dunn, T. J., Baguley, T., \& Brunsden, V. (2014). From alpha to omega: A practical solution to the pervasive problem of internal consistency estimation. British Journal of Psychology, 105(3), 399-412. https://doi.org/10.1111/bjop.12046

Engell, D., Kramer, M., Malafi, T., Salomon, M., \& Lesher, L. (1996). Effects of effort and social modeling on drinking in humans. Appetite, 26(2), 129-138. https://doi.org/10.1006/appe.1996.0011

Gadermann, A. M., Guhn, M., \& Zumbo, B. D. (2012). Estimating ordinal reliability for Likert-type and ordinal item response data: A conceptual, empirical, and practical guide. Practical Assessment, Research, and Evaluation, $17(3), 3-7$. https://doi.org/10.7275/n560-j767

Hartmann, C., Dohle, S., \& Siegrist, M. (2013). Importance of cooking skills for balanced food choices. Appetite, 65, 125-131. https://doi.org/10.1016/j.appet.2013.01.016

Jackson, E. (2015). Connecting people to the source of their food: Changing the way we think about food to improve health. North Carolina Medical Journal, 76(1), 54-56. https://doi.org/10.18043/ncm.76.1.54

Jarpe-Ratner, E., Folkens, S., Sharma, S., Dara, D., \& Edens, N. K. (2016). An experiential cooking and nutrition education program increases cooking self-efficacy and vegetable consumption in children in grades 3-8. Journal of Nutrition Education and Behavior, 48(10), 697-705. https://doi.org/10.1016/i.jneb.2016.07.021

Jilcott Pitts, S. B., Gustafson, A., Qiang, W., Mayo, M. L., Ward, R. K., McGuirt, J. T., Rafferty, A. P., Lancaster, M. F., Evenson, K. R., Keyserling, T. C., \& Ammerman, A. S. (2014). Farmers' market use is associated with fruit and vegetable consumption in diverse southern rural communities. Nutrition Journal, 13, Article 1. https://doi.org/10.1186/1475-2891-13-1

Jilcott Pitts, S. B., Hinkley, J., Wu, Q., McGuirt, J. T., Lyonnais, M. J., Rafferty, A. P., Whitt, O. R., Winterbauer, N., \& Phillips, L. (2017). A possible dose-response association between distance to farmers' markets and roadside produce stands, frequency of shopping, fruit and vegetable consumption, and body mass index among customers in the Southern United States. BMC Public Health, 17, Article 65. https://doi.org/10.1186/s12889-016-3943-7

Jilcott Pitts, S. B., Wu, Q., McGuirt, J., Crawford, T., Keyserling, T., \& Ammerman, A. (2013). Associations between access to farmers' markets and supermarkets, shopping patterns, fruit and vegetable consumption, and health indicators among women of reproductive age in eastern North Carolina, USA. Public Health Nutrition, 16(11), 1944-1952. https://doi.org/10.1017/S1368980013001389

Kahneman, D. (2003). Maps of bounded rationality: Psychology for behavioral economics. The American Economic Review, 93(5), 1449-1475. https://doi.org/10.1257/000282803322655392

Kahneman, D., \& Tversky, A. (1982). The psychology of preferences. Scientific American, 246(1), 160-173. https://doi.org/10.1038/scientificamerican0182-160

Kirby, L. D., Jackson, C., \& Perrett, A. (2007). Growing local: Expanding the western North Carolina farm and food economy. Southern Sustainable Agriculture Research and Education, Appalachian Sustainable Agriculture Project. https://asapconnections.org/downloads/growing-local-expanding-the-western-north-carolina-food-and-farmeconomy-full-report.pdf/ 
Kolb, A. Y., \& Kolb, D. A. (2005). Learning styles and learning spaces: Enhancing experiential learning in higher education. Academy of Management Learning \& Education, 4(2), 193-212. https://doi.org/10.5465/amle.2005.17268566

Lambert, K. G., Neal, T., Noyes, J., Parker, C., \& Worrel, P. (1991). Food-related stimuli increase desire to eat in hungry and satiated human subjects. Current Psychology, 10(4), 297-303. https://doi.org/10.1007/BF02686902

Larson, N. I., Perry, C. L., Story, M., \& Neumark-Sztainer, D. (2006). Food preparation by young adults is associated with better diet quality. Journal of the American Dietetic Association, 106(12), 2001-2007. https://doi.org/10.1016/j.jada.2006.09.008

Leone, L. A., Tripicchio, G. L., Haynes-Maslow, L., McGuirt, J., Grady Smith, J. S., Armstrong-Brown, J., Gizlice, Z., \& Ammerman, A. (2018). Cluster randomized controlled trial of a mobile market intervention to increase fruit and vegetable intake among adults in lower-income communities in North Carolina. The International Journal of Behavioral Nutrition and Physical Activity, 15, Article 2. https://doi.org/10.1186/s12966-017-0637-1

Levitz, L. S. (1976). The susceptibility of human feeding behavior to external controls. In G. A. Bray (Ed.), Obesity in Perspective (pp. 53-60). National Institute of Health. U.S. Government Printing Office.

Liu, P. J., Wisdom, J., Roberto, C. A., Liu, L. J., \& Ubel, P. A. (2014). Using behavioral economics to design more effective food policies to address obesity. Applied Economic Perspectives and Policy, 36(1), 6-24. http://www.peachlab.org/wp-content/uploads/2013/05/Appl.-Econ.-Perspect.-Pol.-2013-Liu-aepp ppt027.pdf

Maher, J., \& Burkhart, S. (2017). Experiential learning for engaging nutrition undergraduates with sustainability. International Journal of Sustainability in Higher Education, 18(7), 1108-1122. https://doi.org/10.1108/IJSHE-01-2016-0010

Marchiori, D., Corneille, O., \& Klein, O. (2012). Container size influences snack food intake independently of portion size. Appetite, 58(3), 814-817. https://doi.org/10.1016/j.appet.2012.01.015

McCormack, L., Laska, M., Larson, N., \& Story, M. (2010). Review of the nutritional implications of farmers' markets and community gardens: A call for evaluation and research efforts. Journal of American Dietetic Association, 110(3), P399-408. https://doi.org/10.1016/i.jada.2009.11.023

McGuirt, J., Jilcott Pitts, S., Ward, R., Crawford, T., Keyserling, T., \& Ammerman, A. (2014). Examining the influence of price and accessibility on willingness to shop at farmers' markets among low-income eastern North Carolina women. Journal of Nutrition Education and Behavior, 46(1), 26-33. https://doi.org/10.1016/i.jneb.2013.06.001

Meiselman, H., Hedderly, D., Staddon, S., Pierson, B., \& Symonds, C. (1994). Effect of effort on meal selection and meal acceptability in a student cafeteria. Appetite, 23(1), 43-55. https://doi.org/10.1006/appe.1994.1033

Padilla, M. A., \& Divers, J. (2013). Bootstrap interval estimation of reliability via coefficient omega. Journal of Modern Applied Statistical Methods, 12(1), 78-89. https://doi.org/10.22237/imasm/1367381520

Perrett, A., Jackson, C., \& Marion, A. (2018). The growth and transition of sustainable production practices in western North Carolina. Appalachian Sustainable Agriculture Project, Local Food Research Center. https://asapconnections.org/wp-content/uploads/The-Growth-and-Transition-of-Sustainable-ProductionPractices-in-WNC.pdf

Raynor, H. A., \& Wing, R. R. (2007). Package unit size and amount of food: Do both influence intake? Obesity, 15(9), 2311-2319. https://doi.org/DOI:10.1038/oby.2007.274

Rainbolt, G. N., Onozaka, Y., \& McFadden, D. T. (2012). Consumer motivations and buying behavior: The case of the local food system movement. Journal of Food Products Marketing, 18(5), 385-396. https://doi.org/10.1080/10454446.2012.685031

Reicks, M., Trofholz, A. C., Stang, J. S., \& Laska, M. N. (2014). Impact of cooking and home food preparation interventions among adults: Outcomes and implications for future programs. Journal of Nutrition Education and Behavior, 46(4), 259-276. https://doi.org/10.1016/j.jneb.2014.02.001

Rolls, B.J. (2003). The supersizing of America: Portion size and the obesity epidemic. Nutrition Today, 38(2), 42-53. https://doi.org/10.1097/00017285-200303000-00004

Rolls, B. J., Roe, L. S., Kral, T. V., Meengs, J. S., \& Wall, D. E. (2004). Increasing the portion size of a packaged snack increases energy intake in men and women. Appetite, 42(1), 63-69. https://doi.org/10.1016/S0195-6663(03)00117-X 
Rolls, B. J., Roe, L. S., \& Meengs, J. S. (2006). Reductions in portion size and energy density of foods are additive and lead to sustained decreases in energy intake. The American Journal of Clinical Nutrition, 83(1), 11-17. https://doi.org/10.1093/ajcn/83.1.11

Rolls, B. J., Roe, L. S., Meengs, J. S., \& Wall, D. E. (2004). Increasing the portion size of a sandwich increases energy intake. Journal of the American Dietetic Association, 104(3), 367-372. https://doi.org/10.1016/j.jada.2003.12.013

Samuelson, W., \& Zeckhauser, R. J. (1988). Status quo bias in decision making. Journal of Risk and Uncertainty, 1, 7-59. https://doi.org/10.1007/BF00055564

Schachter, S., \& Gross, L. (1968). Manipulated time and eating behavior. Journal of Personality and Social Psychology, 10(2), 98-106. http://dx.doi.org/10.1037/h0026285

Schweizer, K., Ren, X., \& Zeller, F. (2019). On modeling the ceiling effect observed in cognitive data in the framework of confirmatory factor analysis. Psychological Test and Assessment Modeling, 61(3), 333-353.

Shiv, B., \& Fedorikhin, A. (2002). Spontaneous versus controlled influences of stimulus-based affect on choice behavior. Organizational Behavior and Human Decision Processes, 87(2), 342-370. https://doi.org/10.1006/obhd.2001.2977

Thaler, R. H., \& Sunstein, C. R. (2009). Nudge: Improving decisions about health, wealth, and happiness (Rev. ed.). Penguin.

Thomson, C. A., \& Ravia, J. (2011). Systematic review of behavioral interventions to promote intake of fruit and vegetables. Journal of the American Dietetic Association, 111(10), 1523-1535. https://doi.org/10.1016/j.jada.2011.07.013

U.S. Department of Agriculture Economic Research Service [USDA ERS]. (2017). Organic market summary and trends. https://www.ers.usda.gov/topics/natural-resources-environment/organic-agriculture/organic-market-overview/

Wang, L, Zhang, Z., McArdle, J., \& Salthouse, T. (2008). Investigating ceiling effects in longitudinal data analysis. Multivariate Behavioral Research, 43(3), 476-496. https://doi.org/10.1080/00273170802285941

Wetherill, M. S., \& Gray, K. A. (2015). Farmers' markets and the local food environment: Identifying perceived accessibility barriers for SNAP consumers receiving Temporary Assistance for Needy Families (TANF) in an urban Oklahoma community. Journal of Nutrition Education and Behavior, 47(2), 127-133. https://doi.org/10.1016/i.jneb.2014.12.008

Winkler, E., \& Turrell, G. (2009). Confidence to cook vegetables and the buying habits of Australian households. Journal of the American Dietetic Association, 109(10), 1759-1768. https://doi.org/10.1016/j.jada.2009.07.006

Wolf, M. M., Spittler, A., \& Ahern, J. (2005). A profile of farmers' market consumers and the perceived advantages of produce sold at farmers' markets. Journal of Food Distribution Research, 36(1), 192-201.

https://doi.org/10.22004/ag.econ.26768 


\section{Appendix}

Table A1. Demographic Comparison of Enrolled Participants who Completed Baseline, Post, and Paired Surveys

\begin{tabular}{lccc}
\hline & $\begin{array}{c}\text { Enrolled participants who } \\
\text { completed Baseline Survey } \\
n=151\end{array}$ & $\begin{array}{c}\text { Post-Survey Respondents } \\
n=79\end{array}$ & $\begin{array}{c}\text { Paired Responses Reported } \\
\text { in the Study } \\
n=55\end{array}$ \\
\hline Average Age & 53 years & 43 years & 45 years \\
\hline \% Identifying as Female & $118 / 151=78 \%$ & $67 / 79=85 \%$ & $47 / 55=85 \%$ \\
\hline UNCA Affiliation (mode) & Student & Student & Student \\
& $87 / 151=58 \%$ & $34 / 79=43 \%$ & $21 / 55=38 \%$ \\
\hline
\end{tabular}

